\title{
Examination of Rail Dampers with Respect to Noise and Vibration Mitigation
}

\author{
Gabriella Csortos ${ }^{1 *}$, Fülöp Augusztinovicz², László Kazinczy ${ }^{\dagger 1}$ \\ 1 Department of Highway and Railway Engineering, Faculty of Civil Engineering, Budapest University of Technology and \\ Economics, H-1117 Budapest, Múegyetem rkp. 3., Hungary \\ 2 Department of Networked Systems and Services, Faculty of Electrical Engineering and Informatics, Budapest University of \\ Technology and Economics, H-1117 Budapest, Magyar tudósok krt. 2., Hungary \\ * Corresponding author, e-mail: csortos.gabriella@epito.bme.hu
}

Received: 05 November 2018, Accepted: 09 April 2020, Published online: 06 May 2020

\begin{abstract}
Nowadays there are more and more possibilities to mitigate noise and vibration emitted by railway transport to the lower levels. Among them, rail dampers with highly viscous properties placed on the rail web, fixed with adhesives or other methods, appeared as a new element in the railway superstructure. The elements are applied to reduce noise and vibration by transforming the vibration energy of the rail web into heat, through their large internal friction. Many companies produce rail web elements and apply them with success abroad. Domestic manufacturers have already appeared in Hungary; however, the installation of these elements is still very limited. This publication is intended to introduce the rail dampers and to demonstrate their efficiency through laboratory and field measurements. Experimental modal analysis was used during the laboratory test to determine the eigenfrequencies, the damping factors and the mode shapes of an experimental rail section, thus analyzing the vibration damping and noise reduction effect of the elements. Field measurements were also carried out at a segment installed with rail web elements in Hungary and its vicinity, under standardized conditions. By averaging measured noise level values for various types of trains, comparable noise reduction of the investigated rail web element can be achieved. The laboratory and field test results confirmed that the rail web elements can be suitable for rolling noise reduction and vibration damping in most of the cases. The results of the measurements provide guidance and information for future development of the elements.
\end{abstract}

\section{Keywords}

railway superstructure, rail dampers, rail absorbers, vibration damping, noise reduction, applied modal analysis

\section{Introduction}

Rail dampers or absorbers are used to reduce the sound radiation resulting from the wheel/rail contact. Due to the relatively small mass and stiffness of the rail web it can easily vibrate, therefore it is considered a weak point of the system acoustically. The rail dampers reduce noise and vibration by transforming the vibration energy into heat, through their large internal friction. One of the well-known basic principles of acoustics is that the most effective way to reduce undesirable vibrations is to focus directly on their source. By installing these elements, we follow this approach, because of the wheel/rail interaction.

In this article, we present various rail dampers and describe their controlled laboratory test which developed to determine the damping efficiency of these elements by using the modal analysis method. In the laboratory, we only examined the vibrations of the rail. Although we know that a train has several other noise sources that together determine the resulting sound pressure level of the railway noise. For instance, if we only focus on the wheel/rail rolling noise generation mechanism, the track contains other components than the rail that also radiate noise (e.g. the sleepers [1], the wheel itself etc.). Finally, we describe the conditions of the field measurement and the results of examined rail damper.

In fact, there are no standardized procedures to measure the efficiency of a rail damper [2]. We present a possible method with experimental modal analysis to determine and improve the efficiency of these elements. We validated this test with field measurement. 


\section{Laboratory tests}

We planned our experiment based on a previous laboratory test conducted at Technische Universität Berlin [3]. However, our measurements provided more detailed results due to the more complex method.

The same conditions, measurement tools and the measuring system was required to determine and compare the effectiveness of rail dampers. The experiment took place in the semi-anechoic room of the Laboratory of Acoustics and Studio Technologies of the Department of Networked Systems and Services of BME.

Due to the laboratory constraints, the tests were carried out on a $120-\mathrm{cm}$ long $60 \mathrm{E} 1$ rail which was fastened with Skl-1 type rail fastening system at a standard distance of $60 \mathrm{~cm}$ to two half L4 type sleepers (Fig. 1).

We tested seven rail dampers with different properties (Table 1). At the request of the manufacturers, the examined elements (Fig. 2 (a-e)) are described with letter code. For the measurements we needed two rails because of the bonded elements. The order of tests on one of the rails: S-T, S-T (bonded), S-F. The adhesive bonding of the S-T-type

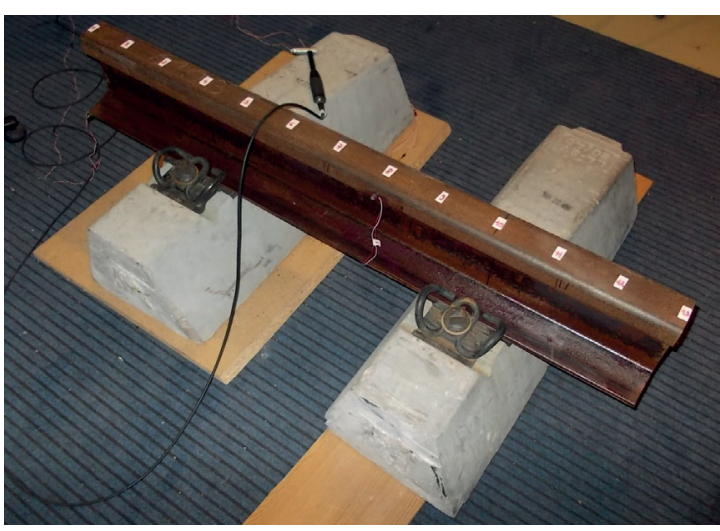

Fig. 1 Mechanical system: undamped rail

was dissolved, after that the S-F-type was bonded to the rail. The order of test on the other rail: SL-A, G1-G4, G3 (bonded). The undamped rails were used as a reference.

We used experimental modal analysis technique to analyze the vibration processes in the rail and to quantify the damping effect of the rail dampers [4-7]. The rail was represented by a wireframe model which consists $13 \times 2$ points. Roving impact hammer excitation was applied to each node

Table 1 Examined rail dampers and their properties

\begin{tabular}{|c|c|c|c|c|c|c|c|}
\hline Type & Profile & Material & $\begin{array}{c}\text { Mass } \\
{[\mathrm{kg}]} \\
{[\mathrm{kg} / \mathrm{m}]}\end{array}$ & $\begin{array}{c}\text { Width } \\
\text { Height } \\
\text { Depth } \\
{[\mathrm{mm}]}\end{array}$ & Fixing method & $\begin{array}{l}\text { Installation } \\
\text { position }\end{array}$ & $\begin{array}{c}\text { Elem. on the rail } \\
{[\mathrm{pcs}]}\end{array}$ \\
\hline \multirow{3}{*}{ S-F } & \multirow{3}{*}{ Fig. 2 (a) } & \multirow{3}{*}{$\begin{array}{c}\text { waste tire rubber powder, } \\
\text { poly-urethane }\end{array}$} & 1.10 & 500 & \multirow{3}{*}{ bonded } & \multirow{3}{*}{$\begin{array}{l}\text { continuously on } \\
\text { the rail web }\end{array}$} & \multirow{3}{*}{$2 \times 2.4$} \\
\hline & & & & 94 & & & \\
\hline & & & 2.20 & 20 & & & \\
\hline \multirow{3}{*}{ S-T } & \multirow{3}{*}{ Fig. 2 (b) } & \multirow{3}{*}{$\begin{array}{c}\text { waste tire rubber powder, } \\
\text { poly-urethane }\end{array}$} & 2,48 & 600 & \multirow{3}{*}{$\begin{array}{l}\text { bonded / } \\
\text { mounted by clips }\end{array}$} & \multirow{3}{*}{$\begin{array}{l}\text { continuously on } \\
\text { the rail web }\end{array}$} & \multirow{3}{*}{$2 \times 2$} \\
\hline & & & & 101 & & & \\
\hline & & & 4.13 & 60 & & & \\
\hline \multirow{3}{*}{ G1 } & \multirow{3}{*}{ Fig. 2 (d) } & \multirow{3}{*}{$\begin{array}{c}\text { waste tire rubber powder, } \\
\text { poly-urethane }\end{array}$} & 5.16 & 600 & \multirow{3}{*}{ mounted by clips } & \multirow{3}{*}{$\begin{array}{l}\text { continuously on } \\
\text { the rail web }\end{array}$} & \multirow{3}{*}{$2 \times 2$} \\
\hline & & & & 115 & & & \\
\hline & & & 8.60 & 60 & & & \\
\hline \multirow{3}{*}{$\mathrm{G} 2$} & \multirow{3}{*}{ Fig. 2 (d) } & \multirow{3}{*}{$\begin{array}{l}\text { waste tire rubber powder, } \\
\text { poly-urethane }\end{array}$} & 5.90 & 600 & \multirow{3}{*}{ mounted by clips } & \multirow{3}{*}{$\begin{array}{l}\text { continuously on } \\
\text { the rail web }\end{array}$} & \multirow{3}{*}{$2 \times 2$} \\
\hline & & & & 115 & & & \\
\hline & & & 9.83 & 60 & & & \\
\hline \multirow{3}{*}{ G3 } & \multirow{3}{*}{ Fig. 2 (d) } & \multirow{3}{*}{$\begin{array}{c}\text { waste tire rubber powder, } \\
\text { poly-urethane }\end{array}$} & 6.63 & 600 & \multirow{3}{*}{$\begin{array}{l}\text { bonded /mounted } \\
\text { by clips }\end{array}$} & \multirow{3}{*}{$\begin{array}{l}\text { continuously on } \\
\text { the rail web }\end{array}$} & \multirow{3}{*}{$2 \times 2$} \\
\hline & & & & 115 & & & \\
\hline & & & 11.05 & 60 & & & \\
\hline \multirow{3}{*}{ G4 } & \multirow{3}{*}{ Fig. 2 (d) } & \multirow{3}{*}{$\begin{array}{c}\text { waste tire rubber powder, } \\
\text { poly-urethane, gravel }\end{array}$} & 10.64 & 600 & \multirow{3}{*}{ mounted by clips } & \multirow{3}{*}{$\begin{array}{l}\text { continuously on } \\
\text { the rail web }\end{array}$} & \\
\hline & & & & 115 & & & $2 \times 2$ \\
\hline & & & 17.73 & 60 & & & \\
\hline SL-A & Fig. 2 (e) & $\begin{array}{c}\text { vulcanized natural rubber } \\
\text { mixture, }\end{array}$ & 6.14 & 430 & mounted by clips & $\begin{array}{l}\text { in the middle } \\
\text { of sleeper span }\end{array}$ & $2 \times 1$ \\
\hline & & steer core & 14.28 & 70 & & & \\
\hline
\end{tabular}




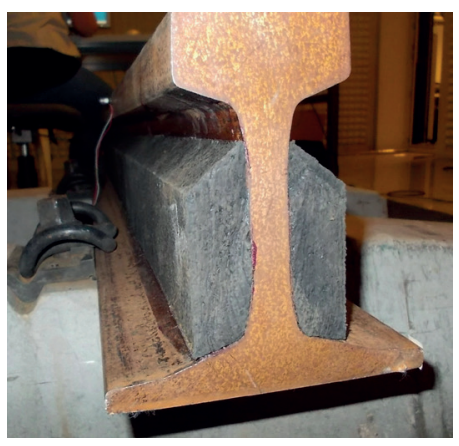

(a)

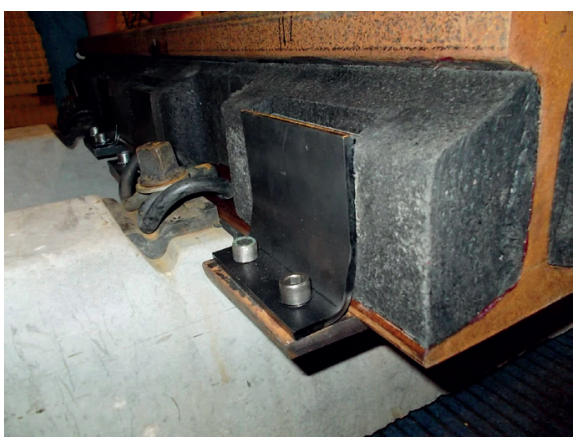

(b)

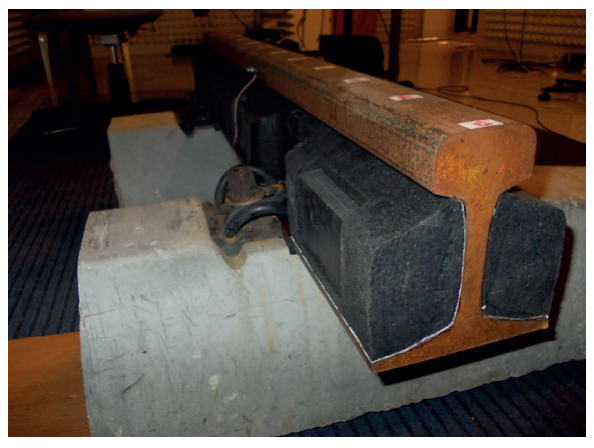

(c)

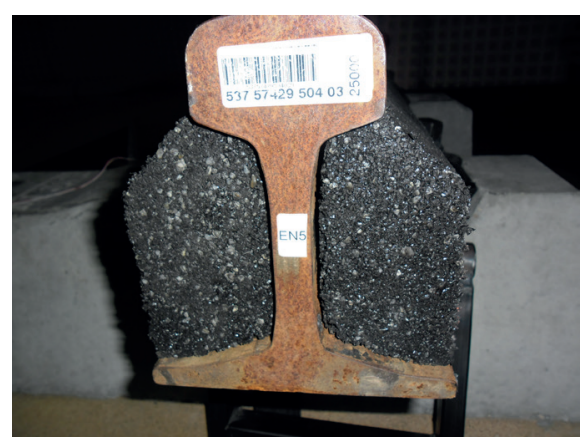

(d)

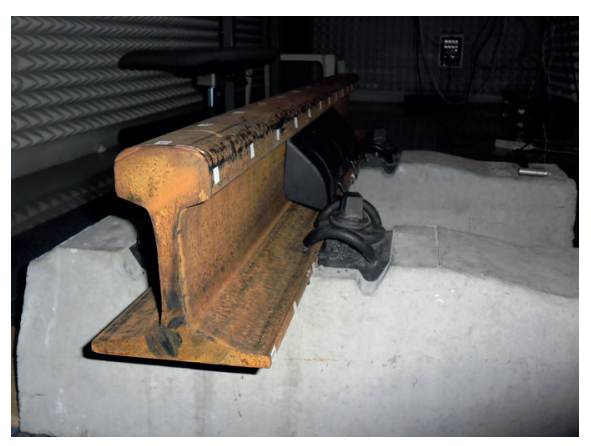

(e)

Fig. 2 Type of rail dampers: (a) S-F, (b) S-T, (c) S-T bonded, (d) G1-G4, (e) SL-A

of the model mesh, while the response was measured by accelerometers in three reference points and by a measuring microphone in the sound field at $1 \mathrm{~m}$ distance from the rail. The vibration reference points were selected on the basis of introductory, finite element (FE) calculations.

Simple models of the rail have earlier been based on the Euler-Bernoulli or Timoshenko beam equations with one- or two-layer mass-spring foundation [8]. According to Thompson [9], none of these models can be applied reliably across the whole frequency range. In order to model the rail as a vibration structure, a double beam model was created [10] to describe the behavior of the vertical vibrations at high frequencies. The results show that the conventional Timoshenko beam model is usable only up to $2000 \mathrm{~Hz}$ because of the rail foot response. There are number of models concerned with quantifying noise reduction effects. The rail radiated noise can be reduced by about 6-8 $\mathrm{dB}$ (A) using the rail absorber according to a finite element model of the railway track [11, 12]. Some guidelines are gained on selection of the types and parameters of the rail absorbers through analysis of the track dynamics. It is found that a large active mass used in the absorber is beneficial to the decay of rail vibration $[13,14]$.

Without the need for complex calculations, we have created a simple Timoshenko beam model by using the MSC Nastran structural FE program. The calculations were also performed on a $120-\mathrm{cm}$ long 60E1 rail. The model mesh consists $1-\mathrm{cm}$ high triangular prisms. To produce the mass and the stiffness matrix, the material properties of the rail are given. During the eigenfrequency analysis we examined the model without any excitation and looked for the first 15 mode shapes without limiting the frequency range. As a result of the analysis, the eigenfrequencies and mode shapes of the model can be calculated, the most important of which are shown in Fig 3.

From the results of the FE-calculations, we decided where to place the vibration sensors (as vibration reference points) on the mechanical system. One sensor was located on the rail head at center of the rail (horizontal direction), on the rail foot one sensor at the end (horizontal direction) and one sensor in the center of the rail (vertical direction).

By measuring the transfer functions between the impact force and acceleration response in more than one point, a multiple input - multiple output system was set up involving the time domain multiple degree of freedom method. (This was necessary because it was assumed from the beginning of the analysis that we will be confronted with multiple, closely spaced eigenfrequencies and similar mode shapes.) In order to obtain global estimates of the system characteristics, the applied parameter estimation method was the least square complex exponential method, implemented by the Test.Lab software package, developed by LMS International [15]. 


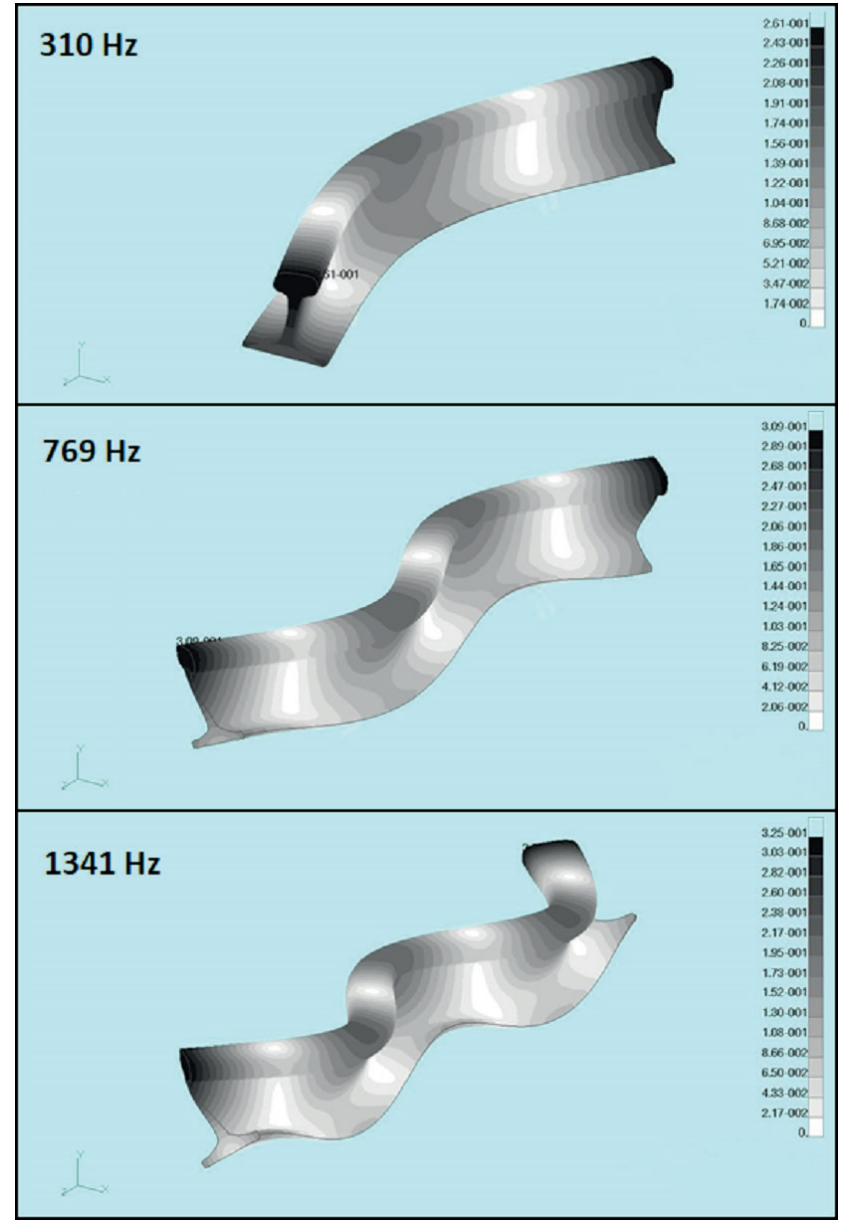

Fig. 3 Results of the FE calculations. 3 of the most important eigenfrequencies and their corresponding mode shapes

\subsection{Vibration damping}

Based on the ratio between responses and excitations, the applied Test.Lab software package determines eigenfrequencies, mode shapes and damping factors of the investigated system. Out of the theoretically obtainable $13 \times 2$ modes, three relevant normal modes were selected. These physically relevant mode shapes could be matched to the FE simulation results and had relevance from the acoustical radiation point of view as well. Based on the modal analysis results, we determined the efficiency of the rail dampers by comparing their damping factors for the selected normal modes (Fig. 4). There are other tests focusing on the first and second pinned-pinned frequencies, for example [16], but also determining the efficiency of the elements by comparing the damping factors.

The degree of effectiveness of the elements can be characterized by damping factors. The higher the value of the damping factor, the more effective vibration damping can be achieved. The difference between damping factors is considered as the result of the tests (Table 2).

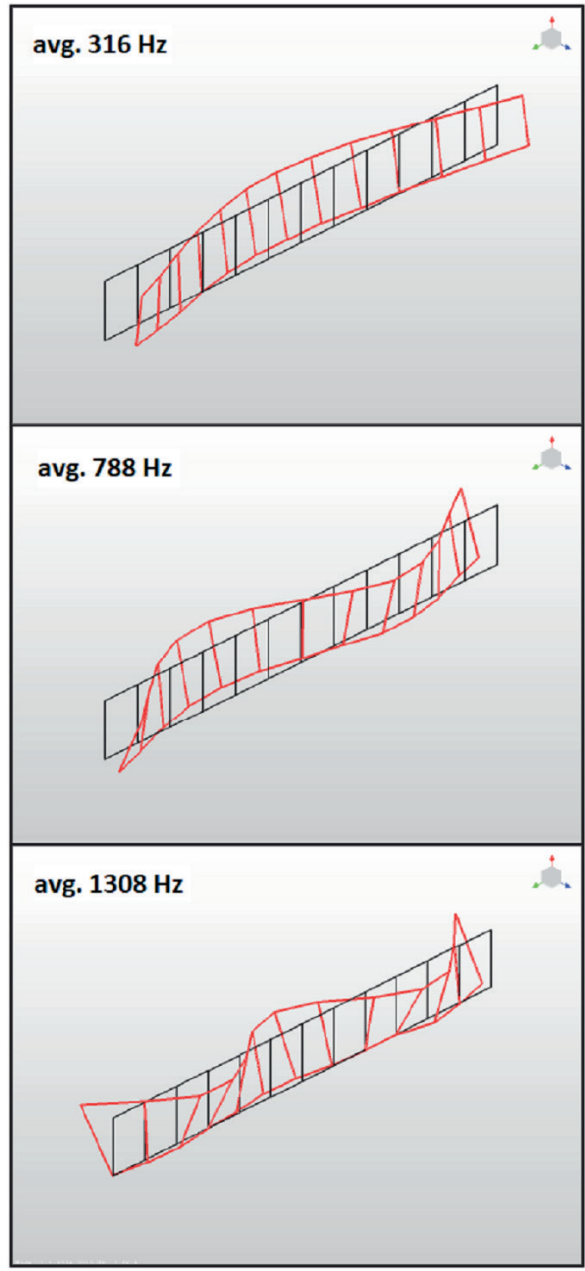

Fig. 4 The wireframe model (black) with $13 \times 2$ points and example results of the selected normal modes (red) with their corresponding averaged eigenfrequencies

It is important to note that the selected normal modes resulted in mode shapes at different frequencies due to the different rail dampers, the reference rails and of course the loosening and tightening of the rail fastenings. Therefore, the values of the resulted eigenfrequencies (from Table 2) were averaged. This averaged value is given for grouping the three mode shapes in Fig. 4 and in the Table 2, but this is not a specific result. Furthermore, it is not only the rail that plays a role in the generation of mode shapes, but also the rail fastenings. Even though we have sought to tighten the rail fastenings in the same way, the shape of the modes depends on the effect of the clamping force. This is the only reason that the symmetry in the mode shapes is reduced in some places.

Comparing the Figs. 3 and 4, it can be seen that the mode shapes calculated by the FE-model and resulting from the measurements of the experimental structure are nearly identical and generated at almost the same frequency. 
Table 2 Comparison of modal parameters of various rail dampers

\begin{tabular}{|c|c|c|c|}
\hline $\begin{array}{l}\text { Type of rail web } \\
\text { element }\end{array}$ & $\begin{array}{c}\text { Eigen } \\
\text { frequency } \\
{[\mathrm{Hz}]}\end{array}$ & $\begin{array}{c}\text { Damping } \\
\text { factor } \\
{[\%]}\end{array}$ & $\begin{array}{l}\text { Difference } \\
\text { of damping } \\
\text { factors }\end{array}$ \\
\hline \multicolumn{4}{|c|}{ Frequency of mode shape: avg. $316 \mathrm{~Hz}$} \\
\hline Undamped & 328 & 0.78 & \\
\hline S-F & 314 & 0.88 & +0.1 \\
\hline S-T & - & - & - \\
\hline S-T bonded & - & - & - \\
\hline Undamped & 321 & 0.87 & \\
\hline G1 & 328 & 4.27 & +3.40 \\
\hline G2 & 329 & 7.03 & +6.16 \\
\hline G3 & - & - & - \\
\hline G4 & - & - & - \\
\hline G3 bonded & 283 & 3.43 & +2.56 \\
\hline Undamped & 321 & 0.87 & \\
\hline SL-A & 310 & 4.19 & +3.32 \\
\hline \multicolumn{4}{|c|}{ Frequency of mode shape: avg. $788 \mathrm{~Hz}$} \\
\hline Undamped & 811 & 1.02 & \\
\hline S-F & - & - & - \\
\hline S-T & 811 & 3.46 & $+2,44$ \\
\hline S-T bonded & 778 & 1.48 & +0.46 \\
\hline Undamped & 774 & 0.58 & \\
\hline G1 & 776 & 1.27 & +0.66 \\
\hline $\mathrm{G} 2$ & 779 & 1.58 & +1.00 \\
\hline G3 & 780 & 1.53 & +0.95 \\
\hline G4 & 791 & 3.29 & +2.71 \\
\hline G3 bonded & - & - & - \\
\hline Undamped & 774 & 0.58 & \\
\hline SL-A & - & - & - \\
\hline \multicolumn{4}{|c|}{ Frequency of mode shape: avg. $1308 \mathrm{~Hz}$} \\
\hline Undamped & 1318 & 0.09 & \\
\hline S-F & 1280 & 1.97 & +1.88 \\
\hline S-T & 1313 & 2.47 & +2.38 \\
\hline S-T bonded & 1330 & 2.00 & +1.91 \\
\hline Undamped & 1302 & 0.11 & \\
\hline G1 & 1304 & 0.47 & +0.36 \\
\hline G2 & 1305 & 0.67 & +0.56 \\
\hline G3 & 1306 & 0.71 & +0.60 \\
\hline G4 & 1308 & 0.95 & +0.84 \\
\hline G3 bonded & 1304 & 2.30 & +2.19 \\
\hline Undamped & 1302 & 0.11 & \\
\hline SL-A & 1314 & 1.06 & 0.95 \\
\hline
\end{tabular}

One can see from Table 2 that at $320 \mathrm{~Hz}$ frequency the expected mode shapes were not generated by G3, G4 and in case of any fixing methods of the S-T elements, the normal modes could not be detected. Also, the element of type $\mathrm{S}-\mathrm{F}$ did not prove to be effective at this frequency.
At a higher frequency, at almost $780 \mathrm{~Hz}$, using the element type S-F, G3 bonded and SL-A, we also could not detect eigenvibrations. The reverse behavior of the S-Ttype element can also be observed here, as only a small damping factor was measurable with its mounted version, but the bonded proved to be quite effective.

We can state that while the F-type is not suitable at low frequencies at all, at higher frequencies, like $1315 \mathrm{~Hz}$, it can be as efficient as the larger and heavier S-T-type element. It is also an important result that the S-T-type element was also the best with adhesive bonding at this frequency. The results of G-types show at any frequency that the more compact and heavier the element, the more efficient it is. The SL-A element mounted only on the middle of sleeper span had remarkably good results at each frequency.

\subsection{Noise reduction}

The microphone was placed at $1 \mathrm{~m}$ from the measuring system. Parallel to the structural frequency response measurements we directly measured the time domain of vibroacoustic impulse responses too, from which the transfer functions of sound radiation could be determined.

The frequency response function resulted from the excitation of the $13 \times 2$ points was averaged. Representing the results from each force excited point together, we get an idea of the range in which a significant sound pressure level is emitted. As an example, the results of the S-type elements are illustrated (Fig. 5).

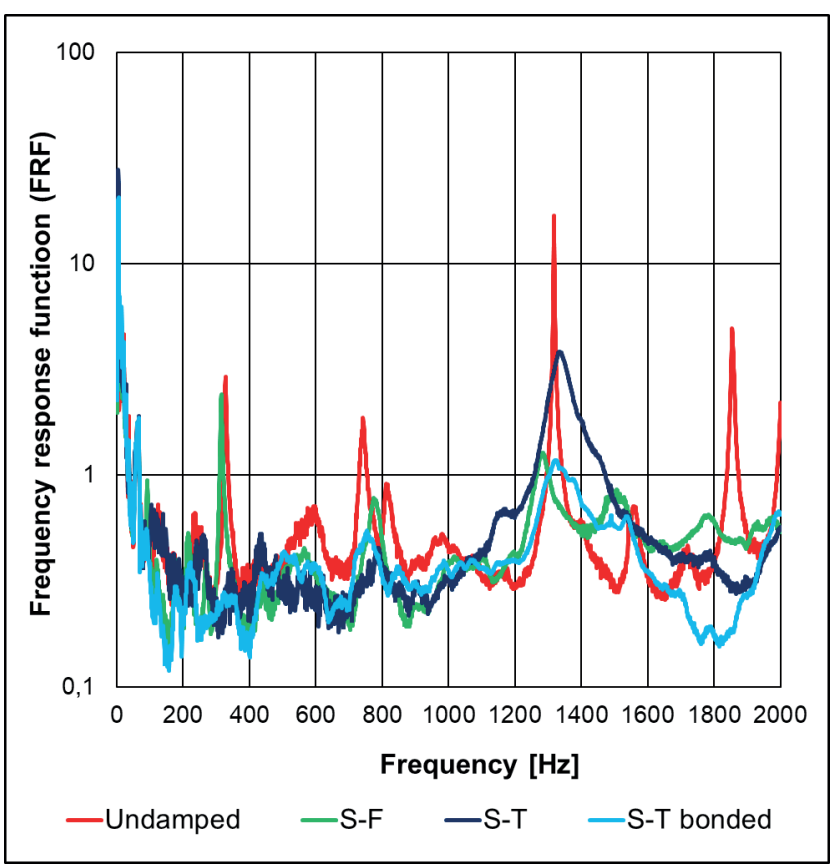

Fig. 5 Results of the S-type rail dampers measured by microphone 
The different peak amplitudes, which can be determined from the graph, indicate the modes. The peaks of the damped rail are shifted on the frequency axis compared to the undamped rails due to the mass and the damping effect of the web elements. The result of the sound radiation can be calculated from the values of the peaks at almost the same frequency (same mode) compared to the value of the peak of the undamped rail. The following basic formula is used to determine the resulting level reduction in $\mathrm{dB}$ for each element:

$\Delta L=20 \cdot \log \left(\frac{p_{2}}{p_{1}}\right)$,

where $p_{1}$ is the undamped rail as reference, and $p_{2}$ is the examined web element. Thereby, it is possible to obtain the value of noise reduction relative to the undamped rail. The results (Table 3) are the values of the peaks of the measured frequency transfer functions in the frequency range that we have chosen, converted to decibel. The negative sign means the negative difference with respect to the peak of the undamped rail. It is important to note that these damping values were achieved on the laboratory sample system, under ideal semi-anechoic conditions.

It can be seen that the same results were obtained during the noise measurements, as in the analysis of vibrations. The result of the S-F element, which was the smallest, is again similar in not being effective at low frequencies, but at higher frequencies, it is also suitable for noise reduction. Another important result is that when the S-T element is bonded to the rail, it gives almost double the damping value as the mounted version.

Table 3 Noise reduction of various rail web elements

\begin{tabular}{lcccc}
\hline & \multicolumn{4}{c}{ Frequency range } \\
$\begin{array}{l}\text { Type of } \\
\text { rail web } \\
\text { element }\end{array}$ & $\begin{array}{c}\text { Max. peak } \\
\text { values }\end{array}$ & $\begin{array}{c}\text { Noise } \\
\text { reduction }[\mathrm{dB}]\end{array}$ & $\begin{array}{c}\text { Max. peak } \\
\text { values }\end{array}$ & $\begin{array}{c}\text { Noise } \\
\text { reduction [dB] }\end{array}$ \\
\hline Undamped & 2.9 & & 16.9 & \\
S-F & 2.4 & -1.7 & 1.3 & -22.4 \\
S-T & 0.5 & -14.9 & 3.8 & -12.9 \\
S-T bonded & 0.3 & -20.4 & 1.2 & -23.1 \\
Undamped & 1.5 & & 10.9 & \\
G1 & 0.4 & -11.0 & 2.7 & -12.1 \\
G2 & 0.3 & -13.1 & 1.3 & -18.6 \\
G3 & 0.3 & -12.8 & 0.4 & -29.3 \\
G4 & 0.3 & -13.8 & 0.4 & -29.2 \\
G-3 bonded & 0.5 & -9.4 & 0.4 & -29.2 \\
Undamped & 1.5 & & 10.9 & \\
SL-A & 0.5 & -9.7 & 3.9 & -9.0 \\
\hline
\end{tabular}

The results show again that the heavier elements are more efficient. Interestingly, based on the values of G3 and G4 elements, after a certain mass, it is not worth applying a more compact element because we cannot achieve higher reduction. Results of noise reduction at higher frequencies are usually more significant because the human ear is the most sensitive in between 1000 and $3000 \mathrm{~Hz}$.

\section{Field measurement}

At present, only the S-F-type rail dampers were installed on the Hungarian railway network. For this reason, we could examine only this type on site. The longest segment is $12 \mathrm{~km}$ between Kápolnásnyék and Dinnyés. The field measurement was carried out at the end of the $12-\mathrm{km}$ segment near Dinnyés. We set up two measuring points at approx. 300-300 $\mathrm{m}$ distance from the segment border and at $5 \mathrm{~m}$ from the axis of the left track. One measuring point was next to the damped- while the other one was next to the undamped track (Fig. 6). The superstructures were the same, except for the built-in rail dampers.

The field measurement and evaluation were carried out according to standard [17]. We used two Brüel \& Kjaer 2250 sound level meters and frequency analyzers. The precision grade instruments were calibrated by using a Larson Davis CAL250 calibrator. The deviation of the calibration values was $0.2 \mathrm{~dB}$, which was corrected during the evaluation. The instruments measured $\mathrm{LA}_{\mathrm{eq}}$ values in each second. From these time series energy equivalent sound pressure levels were derived on the basis of the relevant standard method [18], representing each train pass by one single $\mathrm{dB}(\mathrm{A})$ value. The background noise was on average $45 \mathrm{~dB}(\mathrm{~A})$, therefore the measurements did not require correction. We measured the speed of the passing trains with a radar speedometer. It is important that the results can only be compared if the speed of the passing train is the same at the two points.

We present two of the recorded pass-by events: the result of a Stadler FLIRT (Fig. 7) and a freight train (Fig. 8). The time series of sound pressure levels recorded at the two measurement points can be read from the graphs below (with a timestep of $1 \mathrm{~s}$ ).

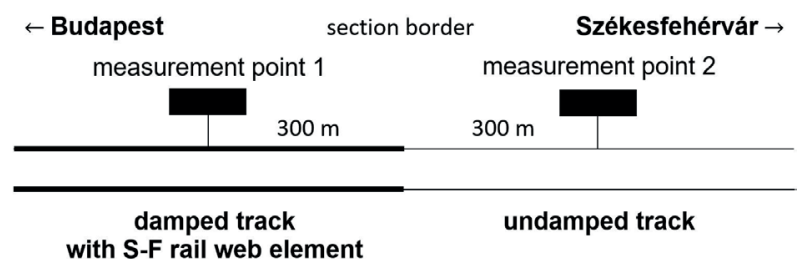

Fig. 6 Conceptual layout of the field measurement 


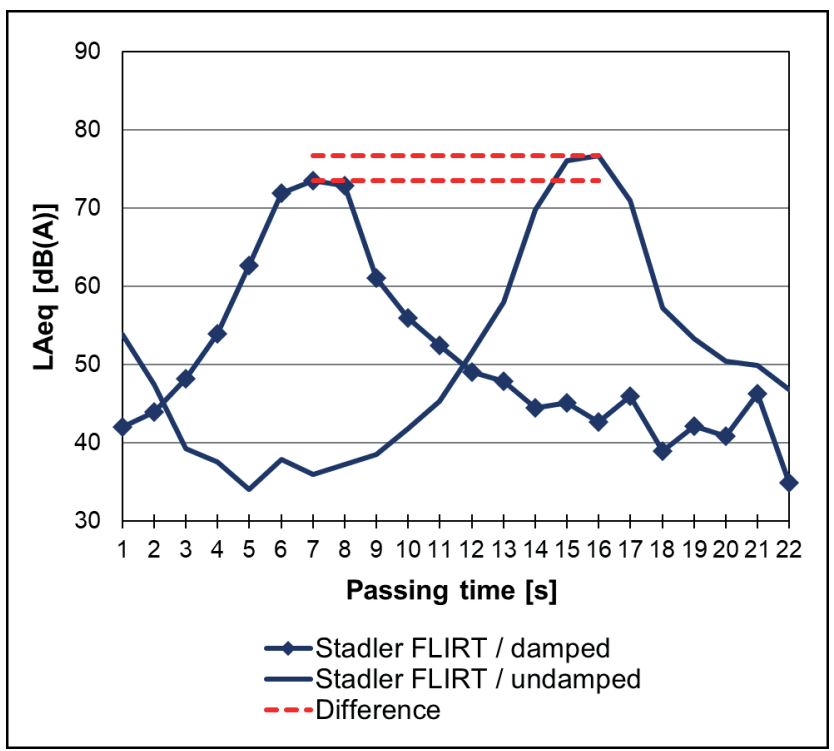

Fig. 7 Sound pressure levels of a Stadler FLIRT train

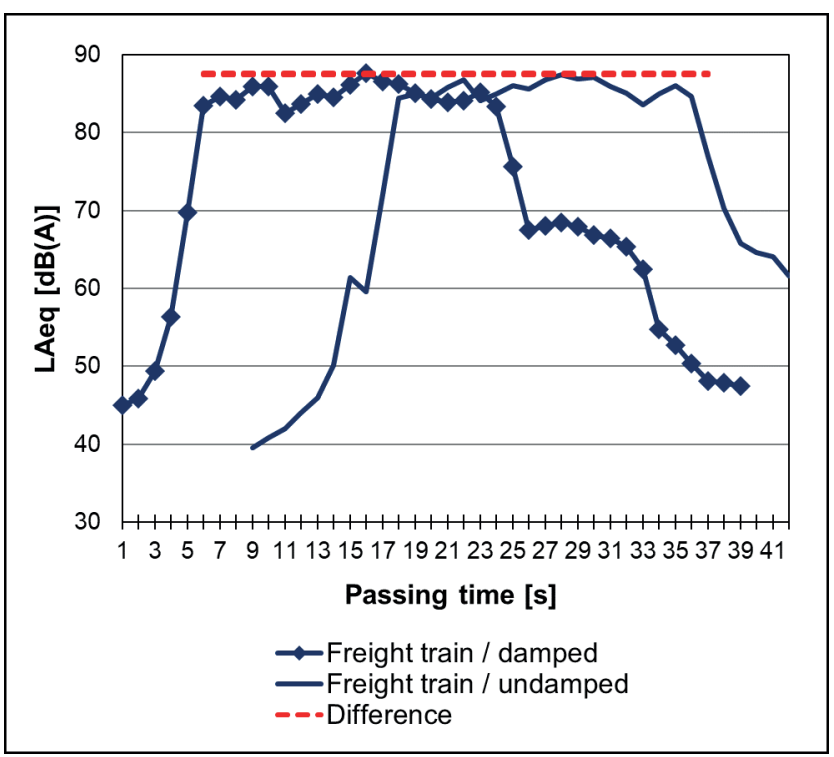

Fig. 8 Sound pressure levels of a freight train

The obtained equivalent sound pressure values are summarized in Table 4. The differences are the noise reduction of S-F-type rail damper. We averaged the measured values for each type of train, as well as we calculated standard deviations. Finally, we averaged all pass-by events to get the result of the damping effect of the S-F-type rail damper (Table 5).

The results met our expectations. It was expected that the rail dampers would not be effective during the passing of a freight train, since the vibration of the rail is not the predominant noise source for this type of train. In case of freight trains, the noise of locomotive or wagons determine the sound pressure levels. However, more than
Table 4 Recorded trains and related noise reductions

\begin{tabular}{lccc}
\hline Type of train & \multicolumn{3}{c}{ Sound pressure level (SPL) $[\mathrm{dB}(\mathrm{A})]$} \\
& Undamped & Damped & Difference \\
\hline & To Budapest & \\
\hline InterCity & 98.2 & 96.5 & -1.7 \\
Stadler FLIRT & 77.3 & 74.9 & -2.5 \\
Stadler FLIRT & 82.2. & 80.4 & -1.8 \\
InterCity & 96.0 & 94.3 & -1.6 \\
Stadler FLIRT & 83.8 & 81.3 & -2.5 \\
& To Székesfehérvár (right track) & \\
\hline Stadler FLIRT & 76.6 & 73.8 & -2.8 \\
InterCity & 91.8 & 89.4 & -2.3 \\
Express & 83.6 & 82.3 & -1.2 \\
Stadler FLIRT & 74.4 & 72.8 & -1.5 \\
Freight train & 85.3 & 84.9 & -0.5 \\
\hline
\end{tabular}

Table 5 Noise reduction of type S-F rail damper

\begin{tabular}{lc}
\hline Type of train & SPL difference $(\mathrm{AVG} \pm \mathrm{SD})[\mathrm{dB}(\mathrm{A})]$ \\
\hline Stadler FLIRT & $-2.2 \pm 0.5$ \\
InterCity & $-1.7 \pm 0.5$ \\
Freight train & $-0.5 \pm$ n. a. \\
All passed train & $-1.8 \pm 0.7$ \\
\hline
\end{tabular}

$2 \mathrm{~dB}(\mathrm{~A})$ noise reduction can be achieved for the modern and quieter Stadler FLIRT trains. Considering the results of all field measurements, the S-F damping elements results in an average $1.7 \mathrm{~dB}(\mathrm{~A})$ noise reduction.

These results are in line with international experience [e.g. 19]. Previously, the national railway company of Switzerland (SBB) has already produced a report on the experience of the rail dampers [20]. The results of the elements have been reviewed for European countries. There is a large variability in the results (because of the different parameters and track/vehicle characteristics), but it can be stated that the maximum noise reduction is around $3 \mathrm{~dB}(\mathrm{~A})$. According to a Hong Kong measurement [21], which was conducted at a curved operational track inside a tunnel, rail dampers can reduce rail vibration by about $10 \mathrm{~dB}(\mathrm{~A})$ and noise level by $3.5 \mathrm{~dB}(\mathrm{~A})$. It is a valuable statement that after installation of rail dampers, the sleeper blocks become the dominant noise sources.

\section{Comparison of laboratory and field measurements}

Sound can be described not only by the temporal movement of the vibrating system but also as the components of the spectrum. The spectrum is made up of divergent intensity sounds at different frequencies. The range of spectrum is between $6.3 \mathrm{~Hz}$ and $20 \mathrm{kHz}$. 
We show the result of only one train (Fig. 9) and we plot the graph only up to $2000 \mathrm{~Hz}$ to be comparable to the laboratory test. The graph shows, for which frequency ranges is the S-F element effective. At this point, laboratory and field measurements can be compared.

In the course of laboratory tests, we could see that the element had reductions in the ranges of 600-800, 1200-1400, and 1800-2000 Hz frequencies (Fig. 5). It can be stated that the S-F-type elements cause noise reduction at all frequencies except for the ranges of 30-70 and 350-600 Hz. At higher frequencies, for which the human ear is the most sensitive, the elements work better. Between 500-2000 Hz, the noise radiated from the rail is the dominant source of the environmental railway noise [22]. The operating ranges of the S-F element are the same, but its efficiency is insignificant. It is expected that greater noise reduction would be achieved by installing elements that have better laboratory results, such as S-T and G4 type elements.

By comparing the numerical results of the two examinations, we see an order of magnitude difference. We examined natural vibrations in laboratory and vibrations at operating conditions at field measurement, therefore the values are significantly different. Nevertheless, the results are comparable in relative terms, which shows that the obtained values follow the same trends.

\section{Discussion}

Based on the results it can be established that the same element bonded to the rail web causes higher noise and vibration damping than the mounted version. However, both fixing methods raise further questions. The disadvantage

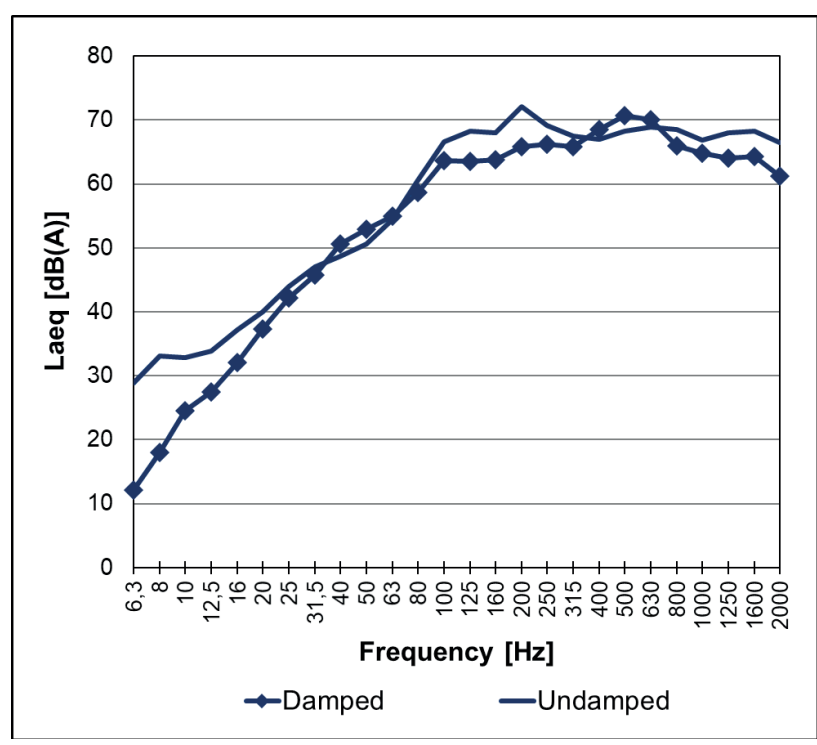

Fig. 9 Frequency spectrum of a Stadler FLIRT train of the bonded elements is that they cannot be removed and reinstalled: it would be hard work and may also lead to breaking the elements. The advantage is that water cannot get in between the element and the rail web, causing further corrosion problems because of the adhesive. On the other hand, the mounted elements with clips can be easily and quickly installed, but at this method the water can easily get in. Further problem is that there is almost no friction and interaction between the damping element and the rail web what the adhesive provides.

The mass (profile, composition) of the elements are influencing the efficiency of the noise and vibration damping. We must strive to produce solid structural elements for the most efficient insulation. An important question at this point is the benefit-cost ratio because the elements do not cause any significant reduction after reaching a certain mass.

The results of field measurement were in line with our expectations and further supported the laboratory work. It is important to know that sound pressure levels are mostly determined by the condition, age, and quality of the trains. Noise can be reduced by web elements if the rolling noise is the predominant noise source. Here, we would like to point out that we examined on the field the lightest and smallest web element. In our view, a heavier element - with better results in the laboratory - can cause better noise reduction under operating conditions. We intend to support this hypothesis with further field measurements.

Further field measurements are also required for verifying the vibration insulation efficiency. If the vibrations of the rail are effectively reduced and thus the vibration path is blocked, the vibrations of the sleepers and the ballast are also expected to decrease. As a result, the life of the track can be increased.

Although we used modal analysis to investigate the effectiveness of the rail web damping elements, there is a more appropriate method that can be performed both in laboratory and in situ. The method is the decay rate measurement [e.g. 2, 22, 23]. It is also worth testing the elements by using this method in the future.

\section{Conclusions}

In this research we examined the noise and vibration effect of different types of rail dampers under laboratory conditions by means of structural modal analysis and vibroacoustic transfer function measuring methods. The real noise reduction of one of these elements was also determined under operating conditions. We also compared the effect of various fixing methods of the elements. 
The noise reduction of the $2.20 \mathrm{~kg}$ and $20 \mathrm{~mm}$ thick element under operating condition is $1.8 \mathrm{~dB}(\mathrm{~A})$ in average. Noise emitted by the multiple-unit trains (FLIRT) was reduced by an average of $2.2 \mathrm{~dB}(\mathrm{~A})$. However, there is no sensible damping effect in case of passing freight trains, obviously, since the dominant source is the vehicle itself.

When evaluating these results, one has to bear in mind that the noise component radiated by the rail is just one component of the noise, generated by the rolling stock and the superstructure together. In the case of freight trains, a number of other, mostly predominating sources do exist, therefore just minimum effect should be expected from the application of rail dampers. The obtained $2.2 \mathrm{dBA}$ reduction for the FLIRT however means that the contribution of the rail vibration is nearly as important as any other component of the noise generation process. ( $3 \mathrm{dBA}$ reduction would mean that the sound energy radiated by the passing train is halved.) Considering that the main railway noise source is the wheel/rail contact and some other sources also exist, one cannot expect much more by reducing - or even by entirely removing - the rail vibration component.

\section{References}

[1] Thompson, D. "Railway Noise and Vibration, Mechanism, Modelling and Means", Elsevier, Oxford, UK, 2008.

[2] Toward, M. G. R., Squicciarini G., Thompson, D. J., Gao, Y. "Estimating the Performance of Rail Dampers Using Laboratory Methods and Software Predictions", In: Proceedings of the 11th International Workshop on Railway Noise, Uddevalla, Sweden, 2013, pp. 47-54.

https://doi.org/10.1007/978-3-662-44832-8_7

[3] Siegemann, J. "Bericht Nr. 186/03 vom November 2003 über die Laborprüfung einer Schienenstegbedämpfung - Im Auftrag der Firma Vossloh Werdohl GmbH" (Report No. 186/03 of November 2003 on the laboratory test of a rail web damper - on behalf of the company Vossloh Werdohl GmbH), Technische Universität Berlin, Berlin, Germany, 2004. (in German)

[4] Formenti, D., Allemang, R., Rost, R., Severyn, T., Leuridan, J. "Analytical and experimental modal analysis", In: Proceedings of the 15th International Seminar on Modal Analysis, Course on experimental modal analysis, Part I., Leuven, Belgium, 1990, pp. 1-114.

[5] Heylen, W., Lammens, S., Sas, P. "Modal Analysis Theory and Testing", 2nd ed., Katholieke Universiteit Leuven, Leuven, Belgium, 1998.

[6] Brown, D. L., Allemang, R. J., Zimmermann, R., Mergeay M. "Parameter Estimation Techniques for Modal Analysis", In: Automotive Engineering Congress and Exposition, Detroit, MI, USA, 1979, Technical Paper No. 790221. https://oi.org/10.4271/790221

[7] Ewins, D. J. "Modal testing: Theory and Practice", Research Studies Press, Taunton, England, 1984
If rail damping elements are required, one should use the element with the highest possible mass while rationalizing production costs. Based on our laboratory results, we recommend the elements with a minimum value of $11-14 \mathrm{~kg} / \mathrm{m}$. The elements should be bonded to the rail web.

Our results presented in this paper clearly point out that rail dampers alone are not sufficient to mitigate the railway noise considerably. However, the purpose of this article was not to present a highly effective noise control method, but to compare various rail dampers and draw conclusions with respect to different types and fixing methods. In the absence of an appropriate standard and taking into account the very limited experience one can collect from real-life measurements, the laboratory work described herein seems to be an appropriate approach to experiment with elements and to iterate the most advantageous geometry, mass and composition.

\section{Acknowledgement}

This paper is dedicated to the memory of Assoc. Prof. László Kazinczy, who has passed away unexpectedly at the time of the review process of this paper.

[8] Esveld, C. "Modern railway track", Version 3.1, MRT Productions, Zaltbommel, Netherlands, 2014. [online] Available at: https://www. esveld.com/Documents/Merge_MRT_3.3SelectionWeb.pdf

[9] Thompson, D. J. "Wheel-rail Noise Generation, Part III: Rail Vibration", Journal of Sound and Vibration, 161(3), pp. 421-446, 1993.

https://doi.org/10.1006/jsvi.1993.1084

[10] Wu, T. X., Thompson, D. J. "A double Timoshenko beam model for vertical vibration analysis of railway track at high frequencies", Journal of Sound and Vibration, 224(2), pp. 329-348, 1999. https://doi.org/10.1006/jsvi.1999.2171

[11] Wu, T. X., Liu, H. P. "Reducing the rail component of rolling noise by vibration absorber: theoretical prediction", Proceedings of the Institution of Mechanical Engineers, Part F: Journal of Rail and Rapid Transit, 223(5), pp. 473-483, 2009. https://doi.org/10.1243/09544097jrrt263

[12] Liu, H. P., Wu, T. X. "Modelling and Performance Analysis of Rail Vibration Absorber by FE and BE Methods", In: Proceedings of the 10th International Workshop on RailwayNoise, Nagahama, Japan, 2012, pp. 135-142. https://doi.org/10.1007/978-4-431-53927-8_16

[13] Wu, T. X. "Attenuating Railway Track Vibration by Rail Absorber for Noise Reduction", Noise \& Vibration Worldwide, 39(9), pp. 14-23, 2008 https://doi.org/10.1260/095745608786348668

[14] Wu, T. X. "On the railway track dynamics with rail vibration absorber for noise reduction", Journal of Sound and Vibration, 309(3-5), pp. 739-755, 2008 https://doi.org/10.1016/j.jsv.2007.07.049 
[15] LMS International "Test.Lab dynamic system analysis software package Ver. 9A", Leuven, Belgium.

[16] Maes, J., Sol, H. "A double tuned rail damper - increased damping at the two first pinned-pinned frequencies", Journal of Sound and Vibration, 267(3), pp. 721-737, 2003.

https://doi.org/10.1016/s0022-460x(03)00736-3

[17] MSZT "MSZ EN ISO 3095:2013 Acoustics. Railway applications. Measurement of noise emitted by railbound vehicles", Hungarian Standards Institution, Budapest, Hungary.

[18] MSZT "MSZ 18150-1:1998 Investigation and rating of environmental noise", Hungarian Standards Institution, Budapest, Hungary, 1998. (in Hungarian)

[19] van Haaren, E., van Keulen, G. A. "New Rail Dampers at the Railway Link Roosendaal-Vlissingen Tested within the Dutch Innovation Program", In: Proceedings of the 9th International Workshop on Railway Noise, Munich, Germany, 2008, pp. 378-383. https://doi.org/10.1007/978-3-540-74893-9_53
[20] Scossa-Romano, E., Oertli, J. "Rail Dampers, Acoustic Rail Grinding, Low Height Noise Barriers", Schweizerische Bundesbahnen SBB, Bern, Switzerland, state of the art report, 2012. [online] Available at: https://uic.org/IMG/pdf/2012_dampers_grinding_lowbarriers.pdf

[21] Ho, W., Wong, B., England, D. "Tuned Mass Damper for Rail Noise Control", In: Proceedings of the 10th International Workshop on RailwayNoise, Nagahama, Japan, 2012, pp. 89-96. https://doi.org/10.1007/978-4-431-53927-8_11

[22] Toward, M., Thompson, D. J. "Laboratory methods for testing the performance of acoustic rail dampers", In: Proceedings of the Acoustics 2012 Nantes Conference, Nantes, France, 2012, HAL-Id: hal-00810837f, pp. 3739-3744. [online] Available at: https://hal. archives-ouvertes.fr/hal-00810837

[23] Betgen, B., Bouvet, P., Squicciarini, G., Thompson, D. J. "The STARDAMP Software: An Assessment Tool for Wheel and Rail Damper Efficiency", presented at AIA-DAGA 2013 Conference on Acoustics, Merano, Italy, March, 18-21, 2013. 